\title{
OVARIAN ENDOMETRIOMAS AND PERITONEAL ENDOMETRIOSIS - DIFFERENT CLINICAL IMPLICATIONS OF THE DISEASE
}

Simone Subtil; Inês Ramalho; Sara Campos; Margarida Figueiredo-Dias

Gynecology Department, Coimbra University Hospital Center (CHUC), Portugal.

Faculty of Medicine of Coimbra University, Portugal.

\section{Problem statement}

Isolated ovarian endometriomas and peritoneal endometriosis are believed to be different expressions of the same etiopathogenic entity. Nevertheless, clinical signs and symptoms, clinical and imagiologic diagnosis, and treatment options usually require individualization according to two main consequent issues: pain severity and infertility. Determining clinical features of patients with both forms of endometriosis can be useful in understanding different outcomes between ovarian endometriomas and peritoneal endometriosis.

\section{Methods}

Surgical diagnosed endometriosis patients $(\boldsymbol{n}=\mathbf{3 8 3})$

(Gynecology Department, Coimbra University Hospital Center:2006-2015)

oSurgical reports were analyzed in order to establish two groups.

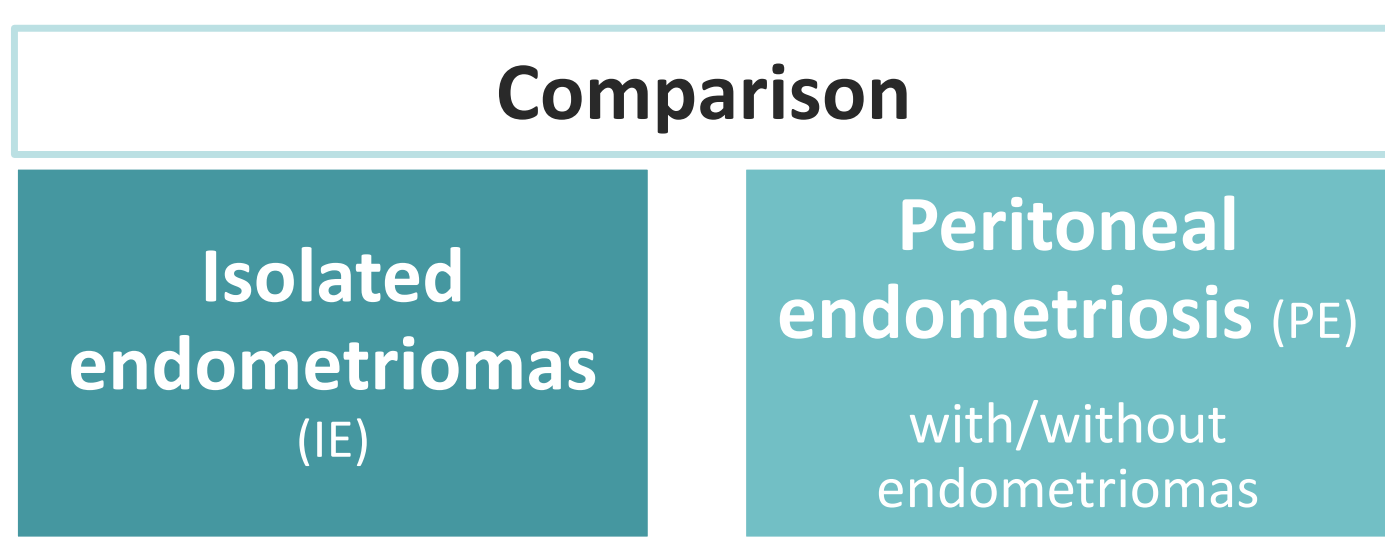

\section{Results}

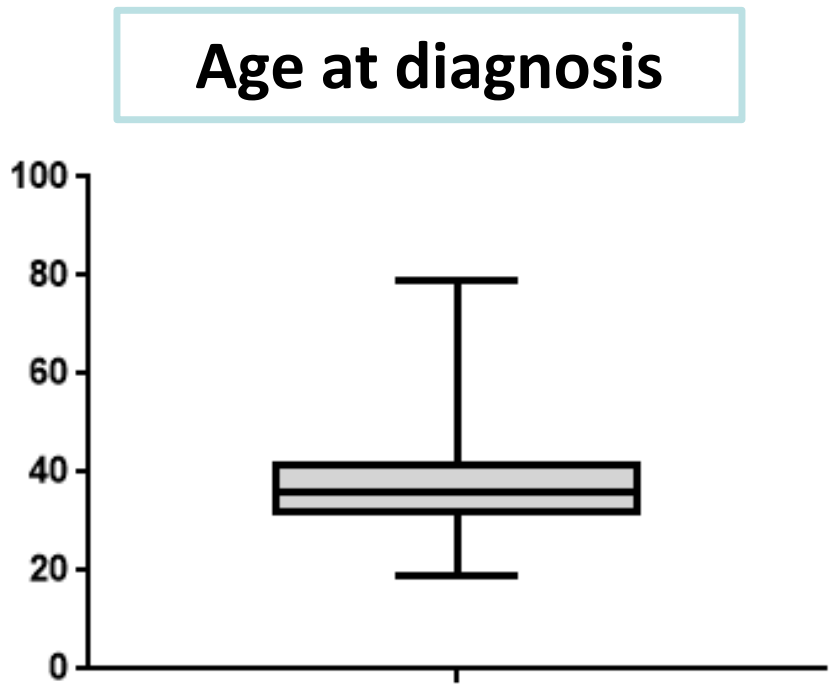

$36,8 \pm 8,0$ years

[19-79]
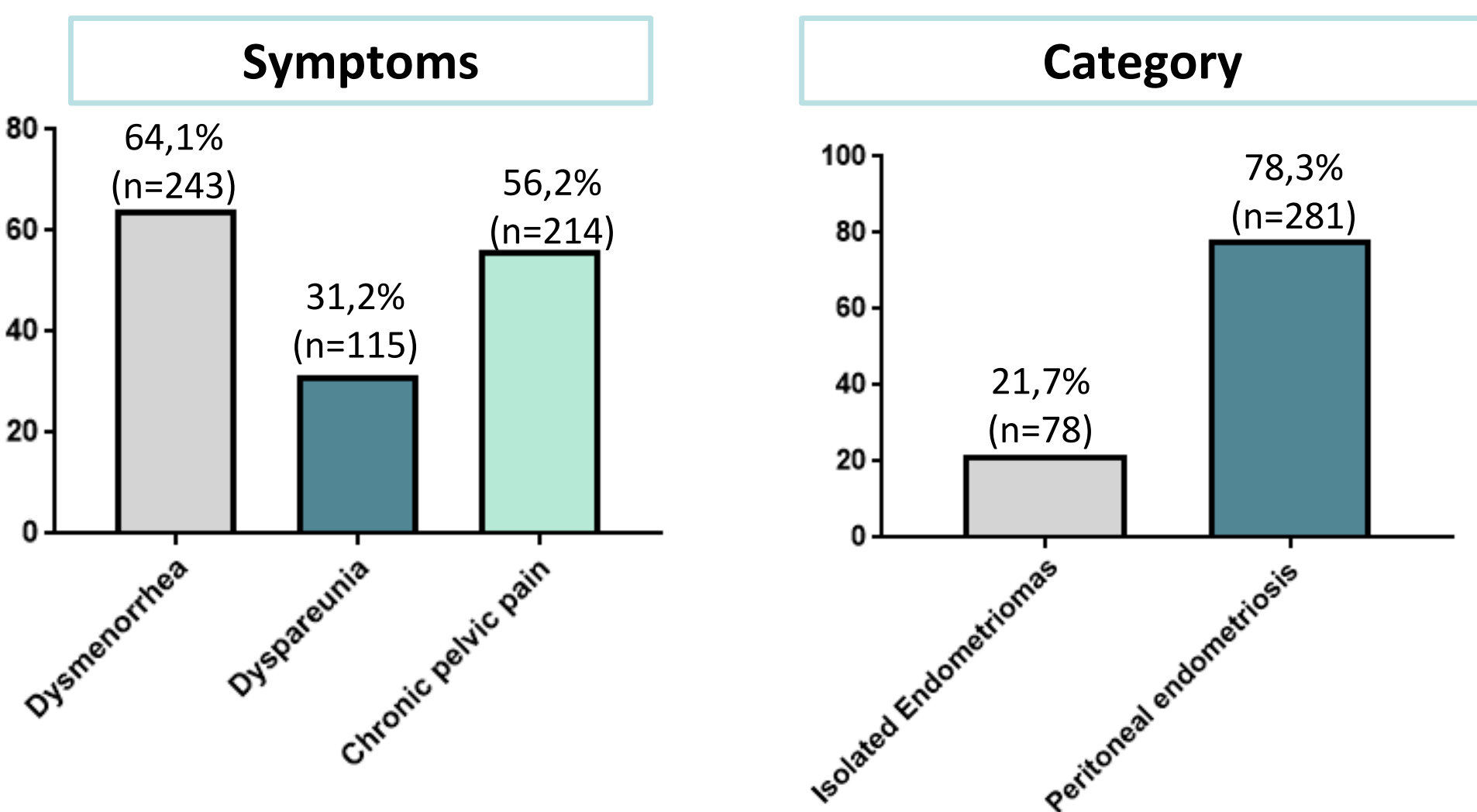

Considering 2 groups: isolated endometriomas versus diffuse peritoneal endometriosis
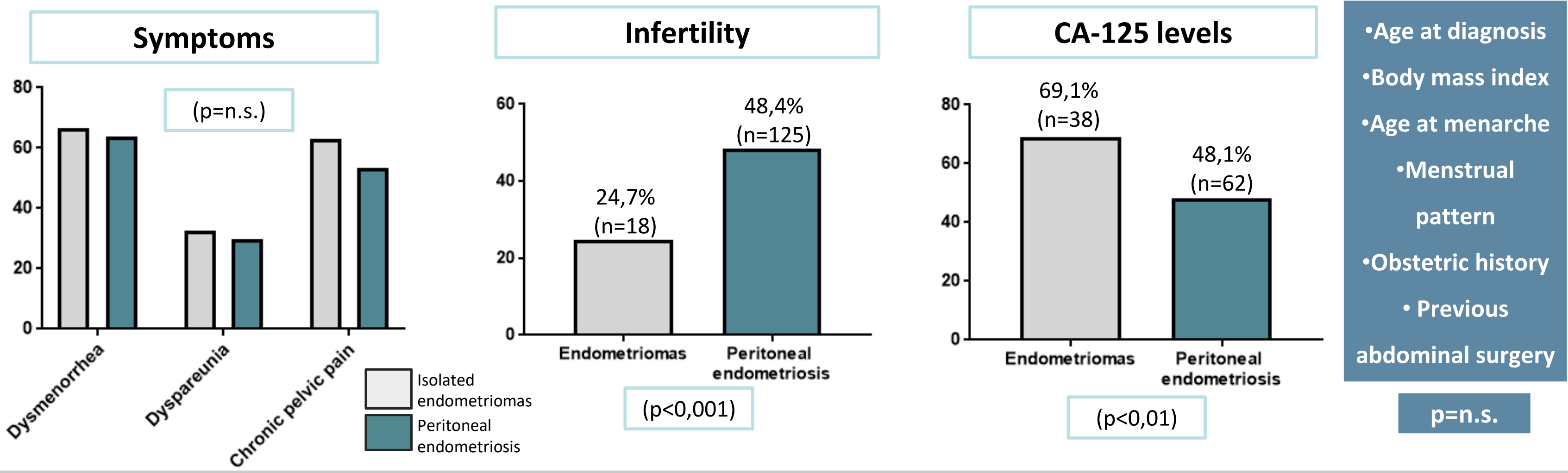

\section{Conclusion}

Isolated ovarian endometriomas and peritoneal endometriosis were similarly associated to pain complaint, mainly chronic pelvic pain and acute cyclic pain. Despite ovarian endometriomas label the disease to advanced stages, peritoneal endometriosis was related to more severe consequences, regarding infertility. CA-125 levels were significantly elevated in isolated ovarian endometriomas when compared to peritoneal endometriosis and this is an interesting observation to consider concerning endometriotic and clear cell ovarian cancer carcinogenesis.
The $25^{\text {th }}$ World Congress on

Controversies in Obstetrics, Gynecology \& Infertility (COGI) All About Women's Health

\section{Vienna, Austria}

November 30 - December 2, 2017 Copyright @ 2017 . Contact:simonefcsubtil@gmail.com 